Revista Española de Antropología Americana ISSN: 0556-6533

https://doi.org/10.5209/REAA.63688

\title{
La ausencia de categorías sociales fundamentadas en la idea de mezcla entre los gunas de Panamá ${ }^{1}$
}

\author{
Mònica Martínez Mauri²
}

Recibido: 5 de junio de 2017 / Aceptado: 4 de mayo de 2018

Resumen. El presente artículo se enmarca en un estudio más amplio dedicado a la conceptualización de la idea de mezcla en diversas sociedades. Partiendo de la idea de que las poblaciones humanas siempre se han desplazado y mezclado, pero no siempre las transgresiones de las fronteras socioculturales han engendrado nuevas categorías basadas en la mezcla, el artículo analiza, por un lado, las posibles causas que explicarían la ausencia de nociones relacionadas con la mezcla y, por el otro, la conceptualización del foráneo en la comarca de Guna Yala (una región autónoma de la costa atlántica de Panamá en la que, según el último censo de población, el 99,5 por ciento de su población se auto-define como guna). Este análisis se fundamenta en una perspectiva diacrónica y una mirada etnográfica sobre la estructura sociopolítica, la ontología, la concepción del parentesco y la procreación en el mundo social guna.

Palabras clave: mestizaje; Panamá; territorio; categoría social; Guna Yala.

\section{[en] The Absence of Social Categories Founded on the Idea of Mixing Among the Guna of Panama}

\begin{abstract}
This paper is part of a larger study devoted to the conceptualization of the idea of mixing in different societies. The point of depart of this article is the idea that whereas humans always migrated and mated, transgressions of socio-cultural group boundaries not necessarily engendered new categories of classification for mixed offspring. By one hand, this article will discuss the possible causes that explain the absence of notions related to mixture, and, by the other, the conceptualisation of the foreign in the Comarca of Guna Yala (an autonomous region on the Atlantic coast of Panama in which, according to the latest population census, 99.5 percent of the population is self-defined as guna). This analysis is based on a diachronic perspective and ethnographic view on the sociopolitical structure, ontology, the conception of kinship and parenthood in the social guna world.
\end{abstract}

Keywords: miscegenation; Panama; territory; social category; Guna Yala.

Sumario. 1. Introducción. 2. El Panamá indígena y la comarca de Guna Yala: el contexto etnográfico. 3. ¿Quién es «indígena», «mestizo», «guna» en la legislación y administración nacional e indígena? 4. Clasificando el mundo humano. 5. ¿Acaso la mezcla no existió? 6. La mezcla y el sistema de parentesco guna hoy. 7. Conclusión: sobre posibles mezclas y mestizajes. 8. Referencias.

Cómo citar: Martínez Mauri, Mònica. 2018. «La ausencia de categorías sociales fundamentadas en la idea de mezcla entre los gunas de Panamá». Revista Española de Antropología Americana 48: 29-42.

\footnotetext{
1 Investigación realizada en el marco del proyecto «Identidades ambivalentes: estudio comparativo de sistemas de clasificación social», HAR2008-04582/HIST, del Plan Nacional I+D+I, 2008-2011, dirigido por Montserrat Ventura i Oller y Verena Stolcke (Universitat Autònoma de Barcelona).

2 Universitat de Barcelona. martinezmauri@ub.edu
} 


\section{Introducción}

Si bien las poblaciones humanas siempre se han desplazado y mezclado, las transgresiones de las fronteras socioculturales no siempre han engendrado nuevas categorías basadas en la mezcla. Esta idea inspiró los trabajos (Ventura et al. 2014) del Grupo de investigación Antropología y Construcción de las Categorías Sociales y Políticas (AHCISP) de la Universitat Autònoma de Barcelona sobre la conceptualización de la idea de mezcla en sociedades indígenas, norteafricanas, indias y europeas. En el presente artículo resumiré algunas de mis aportaciones a este proyecto conjunto, de tres años de duración, centrándome en las nociones - presentes y ausentes- relacionadas con la mezcla y la conceptualización del foráneo en la sociedad guna ${ }^{3}$ de Panamá. Con el fin de abordar esta compleja cuestión, he fundamentado mi análisis en una perspectiva diacrónica y una mirada etnográfica sobre la estructura sociopolítica, la ontología, la concepción del parentesco y la procreación.

En América Latina la noción de mestizaje conoció una gran popularidad a partir del siglo XIX. Aunque no todas las ideologías nacionales han racializado las identidades subalternas ni han intentado domesticarlas con la hibridación o la educación - el caso de Argentina es destacable en este sentido (Briones 2002) -, en países como México y Brasil el mestizaje ha sido una de las ideologías que han formado parte de los procesos de construcción de hegemonías culturales. Esto no ha significado, tal y como ha mostrado Stutzman (1981) para el caso ecuatoriano, que estas ideologías acabasen con la exclusión de la población marcada como afrodescendiente e indígena. El mestizaje y sus políticas han provocado nuevos procesos de racialización marcados por una gran asimetría o incluso con el alineamiento de los mestizos con los indígenas (Cadena 2004).

El punto de partida de este trabajo, y el del proyecto del grupo AHCISP, es el gran éxito y popularidad que en las últimas dos décadas adquirió el concepto de mestizaje, otrora usado por ideologías nacionales, en las ciencias sociales ${ }^{4}$. Desde la década de 1990 el mestizaje, en tanto que categoría de análisis, y sus corolarios -como hibridación-, aplicados al mundo colonial o postcolonial americano (Hall 1992; Young 1995; Werbner y Moodod 1997; Hutnyk 2005), se utilizaron de forma metafórica para referirse a las mezclas culturales resultantes de la disolución de las culturas promovida por el posmodernismo. En las investigaciones del grupo AHCISP nos hemos mostrado críticos con los trabajos que desde las ciencias sociales han mostrado una visión conciliadora del mestizaje. Al igual que otros, consideramos que las múltiples categorías que resultan de este proceso de interrelación son anomalías categoriales que, más que describir una realidad objetiva, expresan las tensiones que emergen de los contextos socioculturales e históricos en los que se producen. Contextos que están marcados por relaciones de poder y un desigual acceso a los recursos. Estas categorías consideradas de «mezclas», en lugar de diluir y conciliar las distintas facciones que integran una sociedad, las oponen y son resultado de prácticas de purificación categorial (Latour 1997).

\footnotetext{
3 Desde marzo de 2011 el pueblo kuna ha adoptado la denominación «guna». En la literatura etnográfica también son conocidos como «tules», «dules», «cunas» o «sanblasinos».

4 Prueba de ello son, por ejemplo, los trabajos de Amselle 1990, Bernand y Gruzinski 1993, Gruzinski 1999, Salomon y Schwartz 1999, Laplantine y Nouss 2001. Para una bibliografia completa sobre el mestizaje $c f$. Boidin et al. 2007. Para una reflexión en torno a las categorias utilizadas en América Latina, $c f$. Boidin 2011.
} 
A continuación me centraré en analizar cómo una sociedad indígena que, desde épocas muy tempranas, conoció la mezcla -voluntaria e involuntaria- con los conquistadores y colonizadores, concibe los seres que resultan de ella. Paradójicamente, tras cinco siglos de contactos con españoles, cimarrones, franceses, ingleses y otras sociedades indígenas del istmo, los gunas se suelen presentar como un pueblo étnicamente homogéneo que practica una estricta endogamia. Su experiencia histórica nos permitirá reflexionar sobre la construcción de fronteras étnicas en el interior de las sociedades latinoamericanas y la permeabilidad de las categorías de origen colonial en los pueblos que fueron sometidos.

\section{El Panamá indígena y la comarca de Guna Yala: el contexto etnográfico}

Según el último censo de población (2010), los indígenas panameños suman 417.559 personas, es decir, significan el 12,3 por ciento de la población censada. Los gunas son 80.526 y constituyen el segundo grupo indígena del país. En estos momentos la población guna es mayoritariamente urbana, siendo la provincia de Panamá ${ }^{5}$ la que concentra más población (40.620 personas), mientras que la comarca de Guna Yala (Kuna Yala o San Blas) tan solo cuenta con 30.458 habitantes. A grandes rasgos, la comarca de Guna Yala se caracteriza por 400 islotes próximos a la costa atlántica panameña y cuenta con 38 islas pobladas, dos comunidades situadas en el continente y ocho en la franja costera.

Guna Yala, marco geográfico de esta investigación etnográfica, es célebre por su autonomía política. Gracias a un proceso histórico complejo y no desprovisto de conflictos, sus habitantes lograron que durante la primera mitad del siglo XX el Estado panameño reconociera oficialmente sus formas de gobierno y territorios. En la actualidad el Congreso General Guna y sus representantes (tres caciques generales) continúan siendo las máximas autoridades en la comarca. El Congreso mantiene el control sobre su territorio conservando la propiedad colectiva de las tierras, limitando la entrada de no gunas a las comunidades y prohibiendo la inversión extranjera y panameña en el interior de sus fronteras. Estas políticas sumamente proteccionistas han frenado la llegada de colonos en el interior de su territorio y han mantenido una población étnicamente homogénea en las comunidades. A diferencia de lo que sucede en muchas comunidades del Darién, las aldeas gunas raramente cuentan con población afrodescendiente, de origen chino o latino. Es significativo notar que, en el último censo de población, de 30.458 personas que residen en la comarca, 30.308 se auto-identifican como indígenas gunas, es decir, el 99,5 por ciento de la población se adscribe a si misma a un solo grupo étnico.

\section{3. ¿Quién es «indígena», «mestizo», «guna» en la legislación y administración nacional e indígena?}

Antes de continuar con el caso guna, es necesario que nos detengamos para presentar las categorías que ha construido el Estado panameño con el fin de organizar y adminis-

\footnotetext{
La provincia de Panamá concentra la gran mayoría de población guna debido a flujos migratorios y al hecho de que una comarca guna, Madungandi (3000 personas), se encuentra en esta demarcación territorial.
} 
trar las poblaciones que alberga su territorio. Un primer elemento a tener en cuenta es que las categorías «indígena» y «guna» están presentes en algunos de los mecanismos administrativos del Estado. Si bien en Panamá el concepto «pueblo indígena» se reconoce en la jurisprudencia y en el censo de población, no tiene una definición oficial (CEPAL/CELADE/BID 2005). La Constitución de 1972 no ofrece una definición que nos facilite comprender qué es ser indígena, pero sí reconoce su existencia y menciona a las «comunidades indígenas» en varios de sus artículos relacionados con la tenencia de la tierra, la división político-administrativa del Estado, la promoción de las lenguas aborígenes o el desarrollo de valores materiales, sociales y espirituales que les son propios. Desde 1940 el censo de población es el mecanismo que, con el objetivo de registrar la población según su identidad étnica, define «indígena» y enumera los grupos indígenas ${ }^{6}$ a los que puede adscribirse dicha población. Sin embargo, no ofrece una definición ni de comunidades ni de pueblos indígenas; simplemente lo hace en su dimensión individual, no colectiva, pues este instrumento está diseñado para contabilizar personas que se consideran a sí mismas indígenas (Martínez 2012).

Respecto a la categoría «mestizo» es necesario señalar que, aunque actualmente ningún mecanismo jurídico o administrativo panameño recoge esta categoría, sí lo hicieron los censos en el pasado. En el de 1920 se utilizó la variable «raza» y se la definió de forma contradictoria: por un lado se reconocía que «las razas humanas se dividen en tres familias principales: blanca o caucásica, amarilla o mongola y negra o melaniana» y que «los principales distintivos que separan las razas humanas se reducen principalmente a consideraciones de orden fisiológico», pero, por el otro, se reconocían como categorías raciales las mezclas, argumentando que son «efecto del cruce de una raza con otra y así tenemos que el mulato es el resultado del cruce del blanco con el negro, el zambo del indio con el negro y el mestizo del blanco con el indio» (DGC 1922 boletín núm. 1: 17). La principal contradicción de estas definiciones raciales estriba en el hecho que, a pesar de que en ningún momento de la argumentación el indio aparecía como una raza aparte, sorprendentemente sí marcaba un nuevo tipo racial derivado de la mezcla con los blancos o los negros.

Es pertinente conectar este dato con las reflexiones de Verena Stolcke (2008) acerca de la construcción de la categoría «mestizo» en el mundo colonial: al igual que los mulatos y los zambaigos, los mestizos no nacieron durante la Colonia, sino que fueron construidos para reforzar las distinciones sociopolíticas de sus progenitores. Tal y como sostiene Stolcke, las categorías sociales «mezcladas» en la América española «no fueron resultado de diferencias preexistentes entre sus progenitores. Sólo cuando los hijos de madres indias y padres españoles fueron designados con la denominación especial de mestizos, las distinciones sociopolíticas y las desigualdades entre sus padres cobraron vida y se institucionalizaron» (Stolcke 2008: 50). En el caso panameño los indígenas no fueron en un primer momento pensados como una raza aparte, pero la aparición del mestizo como una mezcla de razas convirtió automáticamente la categoría «indio» en una categoría racial, marcando una nueva frontera con la población de origen europeo, africano o asiático.

Desde esta clave interpretativa no es sorprendente constatar que, aunque en esa época Panamá se presentaba como un país dominado por las mezclas ${ }^{7}$, la oficina del

\footnotetext{
${ }^{6}$ En 1940 el censo de población enumeraba sólo tres grupos indígenas (guaymíes, gunas y chocoes). Actualmente reconoce ocho (ngäbe, guna, emberá, buglé, wounaan, naso tjerdi, bri bri y bokota).

7 En el boletín del censo se afirmaba que: «De estos cruces existe un número considerable en el Istmo y podría casi
} 
censo continuó manteniendo las categorías raciales para que sus encuestadores pudieran clasificar a la población. De esta manera, las mezclas no diluyeron la esencia de estas categorías, sino todo lo contrario: reforzaron la distinción entre «blancos», «negros»e «indígenas».

En relación con la categoría «guna» y «mestizo», en la legislación guna ninguno de los mecanismos jurídicos aprobados por el Congreso General Guna para mejorar la Ley 16 de 1953 que organiza la comarca de Guna Yala (Reglamento del Congreso General 1993; Ley Fundamental 1995; Estatuto de la Comarca 2000; o las Normas que regulan las actividades turísticas en Guna Yala 2007) aborda la definición de estas nociones. En estos dispositivos legales se habla del pueblo guna, pero no se lo define. Las principales preocupaciones de estos documentos se concentran en marcar las normas que deben regir el autogobierno y los límites territoriales de la comarca.

Un mecanismo jurídico interesante para abordar los criterios de pertenencia son los reglamentos comunitarios. Aunque cada reglamento es único y se adapta a la realidad local de las 52 comunidades de la comarca, en casi todos aparecen ciertas prescripciones matrimoniales o de acceso a los recursos de la comunidad que determinan quién pertenece a la comunidad y quién es considerado extranjero a ella. Así, una disposición frecuente son las multas aplicadas a los comuneros y comuneras que se casan con gunas de otras comunidades. Este tipo de penalizaciones muestra una preferencia por los matrimonios intracomunitarios.

A modo de ejemplo citaré algunas disposiciones sobre la pertenencia a la comunidad del reglamento de la isla de Gardi Sugdub. En primer lugar, al determinar que «al nacer la criatura (niño-niña) automáticamente ya es dueño de todas las instituciones del pueblo. Cuando fallece después de un año recibe $\mathrm{B} / 30.00^{8}$ de las instituciones», muestra que la pertenencia se adquiere por descendencia. En segundo lugar, al declarar que «cuando un comunero renuncia de la comunidad no tiene derecho a recibir los beneficios de las instituciones. Si coopera si tiene derecho», el reglamento pone de manifiesto la importancia que otorgan los gunas a las aportaciones en trabajo, especies o efectivo para ser considerado miembro de la comunidad. Por último, con relación al matrimonio, al afirmar que «el contrayente de otra comunidad antes del matrimonio deberá contar con la certificación de soltería de su comunidad y autorización de sus padres y pagará la suma de B/100.00, el cual no será reembolsado», penaliza las uniones extra-comunitarias. Desde el punto de vista emic se suele justificar esta última disposición aludiendo a los múltiples beneficios que obtiene una persona al convertirse en comunero (básicamente uso de infraestructuras comunitarias como aeropuertos, muelles, etc.). También se acostumbra a interpretar como una expresión de la voluntad de colaborar activamente en el crecimiento del patrimonio comunitario.

A modo de conclusión se puede afirmar que las leyes comarcales y estos reglamentos comunitarios han dificultado la venida de no gunas a la región, han favorecido los matrimonios intracomunitarios y que, por lo tanto, en la actualidad la gran mayoría de habitantes de Guna Yala sean hijos de padre y madre guna.

asegurarse que consideradas las razas en su estado de pureza legítimas sería muy bajo el porcentaje de ejemplares que pudieran resistir el rigor del examen» (DGC 1922: 18)

8 Un balboa (B/) equivale a un dólar estadounidense (US\$) 


\section{Clasificando el mundo humano}

Los gunas se autodenominan dules (personas) y clasifican al resto de los humanos en distintos grupos sociales. Los no indígenas son clasificados en dos grandes grupos: por un lado existen los wagas (latinos) y los wai sidnid (negros) de habla española que habitan cerca de sus fronteras; por el otro los mergi, norteamericanos, zonians o turistas blancos de habla no española. Aunque es incierto saber el origen etimológico de estas nociones, el padre Ibelele Davies ( $† 2010$, q.e.p.d.), uno de mis informantes durante la década de 2000, sostenía que waga podía derivar de walker (explorador) o de la noción guna «wa» (vello). Esta última denominación estaría motivada por el abundante vello corporal de los colonizadores españoles. La noción de mergi, según el padre Ibelele, correspondería a una deformación de american (norteamericano). En ambas definiciones la lengua es el principal elemento diferenciador, y el color de piel un marcador importante, pero no decisivo.

Los otros indígenas de Panamá y América son actualmente conceptualizados como dule, pero hasta hace poco los gunas solían llamar a sus vecinos emberás nia (demonio). La categoría indígena o la extrapolación de la denominación dule a ngäbes, buglés, naso, bribris, emberás o wounan es de uso reciente entre los gunas.

Para los gunas ser dule implica una forma de ser y comportarse en el mundo. Su identidad puede alterarse al compartir substancias con otras gentes. En esta sociedad, cuando una persona comparte comida, bebida, enfermedades y se rodea de gente diferente por un largo periodo de tiempo, es susceptible de incorporar las substancias de otras sociedades y gradualmente transformarse en ellas. La ingestión de dule masi (comida dule, de las personas verdaderas) es muy importante en el devenir guna. La comida, así como otras substancias, los hace diferentes de los otros (blancos, latinos, extranjeros, turistas, etc.). Al igual que algunos grupos amazónicos, los gunas entienden los encuentros culturales como embodied, es decir, los cuerpos experimentan cambios como resultado de la dieta u otras costumbres.

Con el fin de ejemplificar las relaciones que resultan de estas conceptualizaciones creo conveniente citar algunos casos recogidos en el diario de campo durante estos últimos 18 años.

Del 21 al 27 de noviembre de 2002 la comunidad de Gardi celebró una ceremonia llamada biba uet o absoged (fuma de la pipa de la paz o exorcismo, en español). Esta ceremonia tiene lugar en raras ocasiones, se realiza cuando la comunidad sufre varios episodios de epidemias o aparecen espíritus que perturban el equilibrio comunitario. Durante aproximadamente seis días, el especialista ritual llamado absoged canta una larga historia en la casa de la chicha (inna nega) acompañado de la mayoría de hombres de la comunidad. Solo los más jóvenes y los que esperan un hijo quedan fuera del recinto ceremonial. Durante los días que dura el acto los hombres fuman tabaco en la casa de la chicha y con la ayuda de espíritus auxiliares (nuchus y uguruar) combaten los malos espíritus. Toda la comunidad debe observar numerosas prohibiciones durante la realización de la ceremonia; entre ellas, las más destacables son: no mantener relaciones sexuales, no hacer ruido ni salir o entrar de la isla. $\mathrm{Mu}-$ chas comunidades colocan una bandera roja en los muelles principales para avisar a los visitantes que no pueden arribar a la comunidad.

En 2002, cuando me tocó vivir la celebración de esta ceremonia, pasaron varios incidentes que hoy me permiten ilustrar con más detalle las relaciones que los dules mantienen con los «no dules». El primer incidente tiene que ver con mi presencia 
junto a mi pareja en la isla. Las autoridades se dirigieron a nosotros para explicarnos que como extranjeros (wagas) no nos era permitido quedarnos en la isla, pero dado que ya llevábamos cinco meses conviviendo con ellos -comiendo, durmiendo, trabajando... como ellos- podíamos quedarnos si nos comprometíamos a respetar las normas que regían la vida comunitaria esos días.

El segundo incidente tuvo que ver con la llegada de un crucero repleto de turistas a la isla. Normalmente no está permitido recibir visitantes durante los seis días que suele durar la ceremonia, pero las autoridades -bajo la presión de las mujeres- no quisieron dejar pasar la oportunidad de vender valiosas artesanías a los cruceristas. La comunicad decretó una excepción: se permitió el desembarco de los turistas, pero se hizo todo lo posible para mantenerlos alejados de la casa de la chicha, el centro ceremonial. Para lograr tal objetivo las mujeres colocaron telas en lugares estratégicos con el fin de barrar el paso de los turistas a la zona donde se desarrollaba el ritual. Todo el mundo estuvo de acuerdo en que los turistas podían saltarse la prohibición de desembarque, pero todos insistieron en que no podían acercarse a la casa de la chicha.

El tercer incidente está relacionado con la llegada de costeños, habitantes -en su mayoría afrodescendientes - de la costa arriba de Colón ${ }^{9}$, a la comunidad durante los días de la fuma de la pipa de la paz. A diferencia de lo que pasó con los cruceristas extranjeros, a ellos no les fue permitido arribar al muelle de la comunidad con sus embarcaciones. Los días que duró la ceremonia tuvieron que pasar de largo y vender sus productos en las otras comunidades de la zona.

Estos tres incidentes muestran que no todos los no dules son percibidos de la misma manera. Los dules parecen mostrar predilección por los colectivos sociales con los que nunca han mantenido relaciones (turistas) y por los no dules que conviven, comiendo y durmiendo, como y con ellos. En cambio, se mantienen prudentes ante el mantenimiento de contactos frecuentes con poblaciones negras e indígenas vecinas. Otro ejemplo que ilustra esta situación es la prohibición que imperaba hasta el año 2004 en la misma comunidad de Gardi con respecto a los emberás que anualmente visitaban su comunidad para vender cayucos de madera. Hasta ese año los emberás no tenían derecho a dormir en la comunidad; tenían que pasar la noche en el embarcadero durmiendo en su bote. Si bien en la actualidad los emberás son recibidos en una de las casas comunitarias del pueblo, esta norma sigue siendo vigente para los colombianos que recorren la costa de San Blas en canoas vendiendo sus mercancías. Hasta el día de hoy deben pagar un impuesto para poder pisar las islas y no pueden pernoctar en ellas.

Los costeños y los colombianos afrodescendientes (wai sidnid) son los colectivos con los que los gunas mantienen relaciones más distantes. A pesar de ser sus vecinos desde hace casi cinco siglos, todavía es frecuente escuchar comentarios peyorativos hacia ellos. Las relaciones sexuales y matrimoniales con los wai sidnid son raras y socialmente condenadas. En 2011 un anciano de la comunidad de Gardi me comentaba con gran pesar que estaba muy preocupado por los jóvenes, pues a diferencia de lo que él había vivido en su juventud, empezaba a ver que no sentían repulsión por los wai sidnid e incluso empezaban a emparentarse con ellos.

\footnotetext{
9 La costa arriba de Colón se refiere al litoral de la provincia panameña de Colón ubicada al Este de la desembocadura del río Chagres y del Canal de Panamá. Se contrapone a la llamada costa abajo.
} 


\section{5. ¿Acaso la mezcla no existió?}

La manera como los gunas clasifican el mundo muestra la construcción de categorías monoétnicas. En general no utilizan nociones derivadas de las mezclas. En el universo conceptual guna uno es o no es waga, wai sidnid, mergi o dule. Esta no presencia de nociones como mestizo o zambo puede hacer pensar en la ausencia de mezclas con los blancos, latinos o blancos. Podemos formular esta hipótesis en forma de interrogante: ¿Si no existen nociones relacionadas con las mezclas es porque nunca llegaron a producirse? Para responder a esta cuestión me parece acertado hacer mención de algunos trabajos genéticos e históricos sobre el istmo.

El istmo de Panamá fue poblado hace más de 15.000 años. Arqueólogos como Richard Cooke sostienen que los ancestros de las actuales poblaciones indígenas de Panamá pertenecían a dos grupos lingüísticos: chibcha y chocó. Los estudios genéticos muestran una primera disgregación in situ de los chibcha hace entre $8.000 \mathrm{y}$ 6.000 años y lazos de parentesco con los chibchas de Colombia ${ }^{10}$.

Al considerar el cromosoma Y masculino y el ADN autosómico (transmitido de madres a hijos e hijas) se corrobora la importancia de los apareamientos asimétricos en el istmo. En la región comprendida entre Nicaragua y el antiguo territorio de Castilla de Oro predomina la herencia materna indígena en contraposición a la paterna europea y africana. Según el análisis del ADN autosómico de 1.350 muestras panameñas realizado por Perego et al. (2012), el 83,5 por ciento de los haplogrupos son de origen nativo americano, 14,4 por ciento africano y 2,1 por ciento euroasiático y menos del 0,1 por ciento asiático oriental. Estos datos contrastan con las secuencias de cromosoma Y, según las cuales la contribución del linaje paterno europeo es más presente que la de linajes amerindios, africanos y asiáticos. La supervivencia genética desigual en el lado masculino y femenino está relacionada con una desigual mortandad entre hombres y mujeres nativos en el momento de la conquista y a las uniones entre europeos y mujeres indígenas durante el periodo colonial (Achilli et al. 2012).

Los estudios genéticos, además de mostrar que la mezcla ha sido y es una constante en la historia de Panamá, revelan diferencias significativas entre los tres principales grupos indígenas del país. En Guna Yala prevalece el haplogrupo A2 $(77,1 \%)$, mientras que entre los Emberá-Wounaan el C1/D1 (40,9\%) y entre los Ngäbe y Buglé el A2 (50\%) y el B2 (50\%). Otros estudios genéticos, como los de Kolman y Bermingham (1997) entre ngäbes, gunas, emberás y wounan (pueblos pertenecientes a dos grupos lingüísticos distintos, pero geográficamente próximos), también refuerzan la idea que entre ellos no hubo relaciones que comportaran intercambios de genes.

Por último, estudios como los de Barrantes (1993) muestran que las mezclas entre población indígena, afrodescendiente y europea fueron una realidad. Usando marcadores de grupos sanguíneos, Barrantes estima en 2,4 y 2,45 por ciento la tasa de mezcla de la población indígena con caucásicos y negroides, respectivamente.

Los historiadores, igual que los genetistas, también han mostrado que las relaciones con grupos extranjeros se remontan a tiempos muy antiguos. En la época colonial los gunas se enfrentaron a los españoles y se aliaron con ingleses, franceses

\footnotetext{
${ }^{10}$ Richard Cooke: comunicación personal en el marco de la preparación del Congreso Internacional de Americanistas 2015, El Salvador.
} 
y escoceses que frecuentaron sus costas. En algunos momentos algunas de estas relaciones parecen haber dado lugar a matrimonios mixtos. Según fuentes españolas citadas por Langebaek (1991), algunos piratas franceses que erraban por el Caribe se establecieron en tierra firme en 1688 y diez años más tarde, cuando llegaron los escoceses, algunos de ellos se habían casado con mujeres gunas, sin que se hubiera conformado una colonia como tal (Gallup-Díaz 2002). Según Nordenskiöld (1938), el francés llegó a ser una lengua de uso frecuente entre los gunas e incluso algunos líderes, como Juan Sanni, eran hijos de uniones mixtas. Un tratado entre el cacique Uriñaquicha y los españoles, de 1741, hace evidente la presencia y convivencia francesa en el Darién durante el siglo XVIII. En uno de los puntos de la capitulación el cacique guna pide la permanencia de los franceses:

«Espero de la benignidad de V.E. que en lo perteneciente al primer punto de dichos capítulos, en cuanto a la exclusión que V.E. hizo a los franceses que habitan en la parte de mi mando y demás de mis parciales, se sirva conceder a éstos la residencia allí por estar con mujeres naturales de dicha provincia e hijos que han tenido con ellas y connaturalizados de muchos años hasta el presente, y que siendo el número de éstos hasta de sesenta y siete, se hace preciso conceder a la instancia que hacen para no apartarse de aquellos parajes» (Santa Teresa 1956: 268).

La historia guna tal y como es contada por los ancianos es también una historia de contactos y alianzas. En 2012, cuando se hicieron públicos los últimos estudios genéticos del istmo realizados por Perego et al., comenté al argar (intérprete de la tradición) Inaiduli, de la isla de Myria Ubigandub, que los científicos habían llegado a la conclusión que en el pasado los gunas se habían casado con europeos y que estas mezclas se podían trazar hoy en el ADN. En el momento que estaba explicando las conclusiones de los científicos pensé que mi informante rebatiría estas ideas apelando a la pureza de la sociedad guna. Sin embargo, mi sorpresa fue enorme cuando el argar me dio la razón y comentó que eso era muy normal, que en el pasado sus antepasados se habían casado con los franceses y que si entre ellos todavía hoy había gente más clara de piel era porque tenían antepasados europeos.

En definitiva, los contactos con los no gunas son antiguos y dieron lugar a uniones mixtas que tuvieron descendencia guna. Esta situación contrasta con la vivida en el siglo XX y hasta la actualidad, marcada por un gran rechazo de los matrimonios entre dules y wagas, que se materializa con el pago de sanciones o con el abandono de la comunidad. A día de hoy, muchas son las parejas mixtas que se instalan en la ciudad o en otras áreas del país para poder transgredir las normas, casarse y tener hijos. Los descendientes de estas uniones son denominados hijos de wagas (wai mimmi). Recientemente - bajo la influencia del modelo de parentesco panameño y sus ideas sobre la sangre--, también se suele utilizar la noción de oburralet (mezclado) para referirse a las personas nacidas de las uniones entre wagas y gunas, pero aunque se cambie la denominación no son considerados personas pertenecientes al grupo.

\section{La mezcla y el sistema de parentesco guna hoy}

En la comarca de Guna Yala los matrimonios mixtos eran muy raros hasta hace poco. En general, no se aceptaban las uniones de mujeres y hombres gunas con wagas. El hombre o mujer guna que se unía a un waga debía abandonar la comunidad y 
renunciar a sus derechos en tanto que comunero/a. En la comarca apenas había descendencia de uniones mixtas. Varios de mis informantes incluso me comentaron que durante la primera mitad del siglo XX en algunas comunidades todavía se practicaba infanticidio con los hijos o hijas de estas uniones no permitidas. En la ciudad, los descendientes de estas parejas no eran considerados dules, sino que eran denominados wai mimmi (hijos de waga).

A pesar de esta fuerte endogamia, durante el siglo XX se producen algunos matrimonios de hombres gunas con mujeres mergi (misioneras, cuerpos de paz, turistas, etc.). Esta permisibilidad es, en algunas ocasiones, justificada por el carácter matriuxorilocal de la residencia guna. Por norma general, cuando un hombre se casa debe trasladarse a la unidad doméstica de su esposa y trabajar para ella. Partiendo de la teoría clásica de la alianza, Margiotti (2010) interpreta el matrimonio guna como una circulación de hombres entre unidades domésticas y comunidades. En este contexto no sorprende la preferencia de muchos gunas por las hijas. Ellas son fuente de prosperidad y crecimiento para la unidad familiar, mientras que los hijos varones no son garantía de futuro para una pareja tradicional.

Durante los últimos años, la fuerte endogamia que caracterizaba las comunidades de Guna Yala se ha visto debilitada por las presiones externas por explotar el turismo en la región. Las normas comarcales estipulan con claridad que solo los gunas pueden establecer hoteles y promover actividades turísticas en las costas, playas e islas de la comarca. La secretaria de turismo del Congreso General verifica la fuente de las inversiones destinadas a la construcción de instalaciones turísticas para evitar la entrada de capital extranjero. Normalmente el control del congreso y de las comunidades impide la presencia de empresarios extranjeros en la comarca. Sin embargo, en 2016 existían cinco hoteles dirigidos por parejas mixtas. Se trata de un fenómeno reciente pero en expansión, ya que muchas comunidades han aceptado que los extranjeros casados con gunas pasen a formar parte del pueblo. De esta manera los extranjeros (mergis y wagas) pueden establecer un negocio turístico y vivir en las islas. Un hecho interesante es que, mientras no parece cuestionarse la pertenencia de los casados/as con gunas, no está clara la de su descendencia. Hasta el día de hoy no hay consenso sobre la identidad de los hijos de estos matrimonios mixtos, lo que pone en cuestión su derecho a la herencia.

Esta aparente imposibilidad de la mezcla en la descendencia contrasta con la concepción de la procreación en la sociedad guna. Tal y como ha mostrado Margiotti (2010), el papel de hombres y mujeres en la procreación es proporcional. Para los gunas la gestación se produce tras la mezcla de fluidos vaginales y semen en el útero materno. La aportación del padre y la madre es, por lo tanto, igual de importante. El hecho de que durante la gestación ambos deban respetar una serie de iset (prohibiciones, tabúes) ejemplifica esta proporcionalidad.

Es difícil encontrar una sola explicación a la imposibilidad de la mezcla en el sistema de clasificaciones sociales de los gunas. Si nos remitimos a la ontología que rige la sociabilidad guna, observamos que para la mayoría de los habitantes de Guna Yala, los humanos y los no humanos comparten una misma interioridad pero adoptan formas físicas diferentes. Su modelo ontológico puede por lo tanto ser considerado animista (Descola 2005). Según este modelo las diversas especies sociales, humanas y no humanas, se comunican según los términos de la sociabilidad humana dando lugar a una concepción ontológica continua. Pero esta situación contrasta con lo que sucede con otros humanos no considerados dules (personas). 
Los humanos no gunas, los llamados mergis, wagas o wai sidnid, a pesar de tener una forma física parecida, no comparten la misma interioridad que los habitantes de Guna Yala. Su forma de ser, fundamentada en una alimentación diferente, en una sociabilidad extraña y en unos principios espirituales no tratados con medicina guna, los hace interiormente diferentes. Esta diferenciación -producida por la sociabilización, no por su naturaleza- impide la mezcla entre diferentes grupos sociales de la especie humana.

En definitiva, la perspectiva ontológica puede arrojar luz a la hora de entender esta dificultad por concebir la mezcla humana, pero no debemos restar importancia al contexto político y económico en el que se desarrolla este sistema animista. Seguramente la historia de contactos -tanto violentos como pacíficos- con las poblaciones foráneas, ha favorecido la formulación de normas sociales encaminadas a mantener el control territorial. Es necesario tener presente que los principales resultados de esta política matrimonial son, por un lado, la homogeneidad étnica de la población de Guna Yala y, por el otro, la no penetración de capitales transnacionales en la región. Para poder acceder a los recursos de la comarca solo existe un requisito: ser guna. En definitiva, negando la mezcla los individuos se incluyen o se excluyen del grupo de forma muy clara.

\section{Conclusión: sobre posibles mezclas y mestizajes}

La función clasificatoria de los humanos, como decían Durkheim y Mauss (1903), no debe considerarse como un hecho simple o innato. Clasificar los seres, las especies, los acontecimientos y los hechos en géneros o especies no es baladí. Los seres humanos no clasificamos en función de hechos diferenciales, sino todo lo contrario: lo que determina los sistemas de clasificación sociocultural son las voluntades diferenciadoras inspiradas por las condiciones sociopolíticas y/o simbólicas, y sus modos de reproducción. Sus consecuencias sobre la regulación del sexo y la sexualidad son inmediatas en razón de su importancia en la gestación de categorías socioculturales (Ventura i Oller et al. 2014).

Tal y como han mostrado los pioneros estudios de Verena Stolcke (1975, 2004 y 2008) y los trabajos del grupo AHCISP, los sistemas de clasificación sociocultural son construcciones históricas ligadas a las estructuras y a los contextos sociopolíticos, pero también a las normas de reproducción socio-culturales -el control de la sexualidad y la filiación- características de una sociedad en un momento dado. En el caso guna esto se hace evidente al ver la contradicción entre los principios imperantes en la concepción de la procreación (proporcionalidad entre padre y madre) y en la ontología (continuidad o discontinuidad entre seres), con la inviabilidad de las parejas mixtas. A diferencia del siglo XVII y XVIII, cuando los matrimonios entre gunas y franceses eran corrientes, durante los siglos XIX y XX la norma ha sido la condena de los matrimonios extra-comunitarios y mixtos (sobre todo con población negra o latina). El control de la sexualidad de las mujeres -marcado por la exclusión de aquellas que se unían a un no guna- ha facilitado la uniformidad étnica en una sociedad regida por el principio de la matriuxorilocalidad.

Como bien muestra la experiencia histórica guna, el contexto sociopolítico o las concepciones del ser humano que operan en las lógicas de la alianza o de la descendencia juegan un papel central a la hora de conceptualizar las mezclas y al asignar 
a las personas a determinados grupos sociales a lo largo de varias generaciones. Las intersecciones entre las estructuras socioculturales y las políticas, así como sus modos de reproducción, marcan las formas de entender las mezclas. En este sentido, hacemos nuestra la máxima de Pouillon según la cual «on ne classe pas parce qu'il y a des choses à classer; c'est parce qu'on classe qu'on en découvre» (Pouillon 1998: 122). Las mezclas, transgrediendo las fronteras taxonómicas, presuponen la existencia de identidades originarias puras que se reifican y refuerzan en lugar de disolverse (Young 1995). Su ausencia tiende a excluir o integrar a los diferentes, posibilitando la conformación de sociedades étnicamente homogéneas.

Resulta paradójico constatar que la categoría de mestizo se forjó en los inicios de la sociedad colonial hispano-americana, pero que numerosas sociedades indígenas -ingredientes fundamentales en la invención de la noción de mestizo- no suelen poseer categorías sociales relacionadas con las mezclas. Como acabamos de presentar, este parece ser el caso de los gunas. Una sociedad que no cuenta con nociones que expresen ambigüedad. Una sociedad en la que se puede ser dule, waga o mergi, pero que tradicionalmente no permite la producción de seres humanos híbridos.

El caso guna, así como otras investigaciones conducidas por el grupo AHCISP, nos llevan a concluir que el mestizaje, como toda categoría social, está socioculturalmente construido. En tanto que investigadores en ciencias sociales debemos seguir interrogándonos sobre las razones que en ciertas circunstancias hacen posible que uniones o alianzas produzcan la idea de mezcla, mientras que en otras, como en el caso aquí estudiado, las hacen inviables. Solo así podremos dar fe de la gran diversidad de principios que rigen la vida social de las poblaciones humanas.

\section{Referencias}

Achilli, Alessandro, Richard Cooke, Jorge Motta y Ugo Perego. 2012. Descifrando el genoma panameño. Memoria de las conferencias dictadas el martes 16 de octubre 2012. Panamá: Biomuseo. http:/social.biomuseo.com/boletinlunallena/wp-content/themes/ twentyeleven/pdf/genoma.pdf.

Amselle, Jean Loup. 1990. Logiques métisses. Anthropologie de l'identité en Afrique et ailleurs. París: Payot.

Barrantes, Ramiro. 1993. Evolución en el Trópico: Los amerindios de Costa Rica y Panamá. San José: Editorial de la Universidad de Costa Rica.

Bernand, Carmen y Serge Gruzinski. 1993. Histoire du Nouveau Monde. Les métissages (1550-1640), vol. 2. París: Fayard.

Boidin, Capucine. 2011. «Mestizaje, mestiçagem, métissage: useful concepts? », en Europe in Black and White: Immigration, Race and Identity in the Old continent, Manuela Ribeiro Sanches, dir., pp.173-184. Bristol: Intellect .

Boidin, Capucine, Gilles Havard, Frédérique Langue, Mónica Martínez Mauri y Mônica Raisa Schpun. 2007. «Métissages. Une bibliographie collective axée sur les Amériques». Nuevo Mundo. Mundos Nuevos 7 (En línea). https;//doi.org/10.4000/nuevomundo.6813.

Briones, Claudia. 2002. «Mestizaje y blanqueamiento como coordenadas de aboriginalidad y nación en Argentina». Runa 23 (1): 61-88.

CEPAL/CELADE/BID. 2005. Los pueblos indígenas de Panamá: diagnóstico sociodemográfico a partir del censo del 2000. Santiago de Chile: CEPAL. 
Cadena, Marisol de la. 2004. Indígenas mestizos: raza y cultura en el Cusco. Lima: Instituto de Estudios Peruanos.

Descola, Philippe. 2005. Par-delà nature et culture. París: Gallimard.

DGC-Dirección General del Censo. 1922. Censo Demográfico de la Provincia de Panamá 1920. Boletín núm 1. Panamá: Imprenta Nacional.

Durkheim, Émile y Marcel Mauss. 1903. «De quelques formes primitives de classification. Contribution à l'étude des représentations collectives». Année Sociologique 6: 1-72.

Gallup-Diaz, Ignacio. 2002. The Door of the Seas and Key to the Universe: Indian Politics and the Imperial Rivalry in the Darién, 1640-1750. E-Book. Nueva York: Columbia University Press.

Gruzinski, Serge. 1999. La pensée métisse. París: Fayard.

Hall, Stuart. 1992. «New Ethnicities», en 'Race', Culture and Difference, James Donald y Ali Rattansi, eds., pp. 252-259. Londres: Sage.

Hutnyk, John. 2005. «Hybridity». Ethnic and Racial Studies 28 (1): 79-102.

Kolman, Connie G. y Eldredge Bermingham. 1997. «Mitochondrial and Nuclear DNA Diversity in the Chocó and Chibcha Amerinds of Panama». Genetics 147 (3): 1289-1302.

Langebaek, Carl H. 1991. «Cuna Long Distance Journeys: The Result of Colonial Interaction». Ethnology 30 (4): 371-380.

Laplantine, François y Alexis Nouss. 2001. Métissages. De Arcimboldo à Zombi. París: Pauvert.

Latour, Bruno. 1997. Nous n'avons jamais été modernes. París: La Découverte.

Margiotti, Margherita. 2010. Kinship and the Saturation of Life among the Kuna of Panamá. Tesis doctoral. University of Saint Andrews.

Martínez Mauri, Mònica. 2012. «The Social and Political Construction of Racial and Ethnic Categories in National Censuses of Panama, 1911-2010», en Everlasting Countdowns: Race, Ethnicity and National Censuses in Latin American States, Luis Fernando Angosto Ferrández y Sabine Kradolfer, eds., pp. 155-184. Cambridge: Cambridge Scholars Publishing.

Nordenskiöld, Erland. 1938. An Historical and Ethnological Survey of the Cuna Indians. Comparative Ethnographical Studies 10. Gotemburgo: Göteborgs Museum, Etnografiska Avdelningen.

Perego, Ugo A., Hovirag Lancioni, Maribel Tribaldos, Norman Angerhofer, Jayne E. Ekins, Anna Olivieri, Scott R. Woodward, Juan Miguel Pascale, Richard Cooke, Jorge Motta y Alessandro Achilli. 2012. «Decrypting the Mitochondrial Gene Pool of Modern Panamanians». PLoS ONE 7 (6): e38337. https://doi.org/10.1371/journal.pone.0038337.

Pouillon, Jean. 1998. «Appartenance et identité». Le Genre Humain 2: 112-122.

Salomon, Frank y Stuart B. Schwartz, eds. 1999. The Cambridge History of the Native Peoples of the Americas. Volume 3: South America. Cambridge: Cambridge University Press.

Santa Teresa, Severino de. 1956. Historia documentada de la Iglesia en Urabá y el Darién: desde el descubrimiento hasta nuestros días, vol. IV. Bogotá: Biblioteca de la Presidencia de la República de Colombia.

Stolcke (Martinez-Alier), Verena. 1974. Marriage, Class and Colour in Nineteenth Century Cuba: A Study of Racial Attitudes and Sexual Values. Cambridge: Cambridge University Press.

- 2004. «A New World Engendered: The Coming into Being of Mestizos», en A Companion to Gender History, Teresa A. Meade, y Merry E. Wiesner-Hanks, dir., pp. 371389. Oxford: Blackwell Publishing. 
- 2008. «Los mestizos no nacen, se hacen», en Identidades ambivalentes en América Latina (siglos XVI-XXI), Verena Stolcke y Alexandre Coello, eds., pp. 17-58. Barcelona: Ed. Bellaterra.

Stutzman, Robert. 1981. «El Mestizaje: An All-Inclusive Ideology of Exclusion», en Cultural Transformations and Ethnicity in Modern Ecuador, Norman E. Whitten, Jr. ed., pp. 45-94. Urbana: University of Illinois Press.

Ventura i Oller, Montserrat; Alexandre Surrallés, Maite Ojeda Mata, Josep Lluis Mateo Dieste, Mònica Martínez Mauri, Sabine Kradolfer, Pablo Domínguez, Alexandre Coello, Montserrat Clua i Fainé, Alice van den Bogaert y Verena Stolcke. 2014. «Métissages: étude comparative des systèmes de classification sociale et politique». Anthropologie et Sociétés 38 (2): 229-246.

Werbner, Pnina y Tariq Modood, eds. 1997. Debating Cultural Hybridity: Multicultural Identities and the Politics of Anti-Racism. Londres: Zed Books.

Young, Robert J. C. 1995. Colonial Desire: Hybridity in Theory, Culture and Race. Londres: Routledge. 